\title{
Uma Análise de Concepções Sobre a Criança e a Inserção da Infância no Consumismo
}

\author{
An Analysis Of Conceptions About The Child And The \\ Childhood's Insertion In Consumption
}

Un Análisis De Concepciones Sobre El Niño Y La Inserción De

La Infancia En El Consumismo

Tiago Bastos de Moura,

Flávio Torrecilas Viana \&

Viviane Dias Loyola

Universidade FUMEC
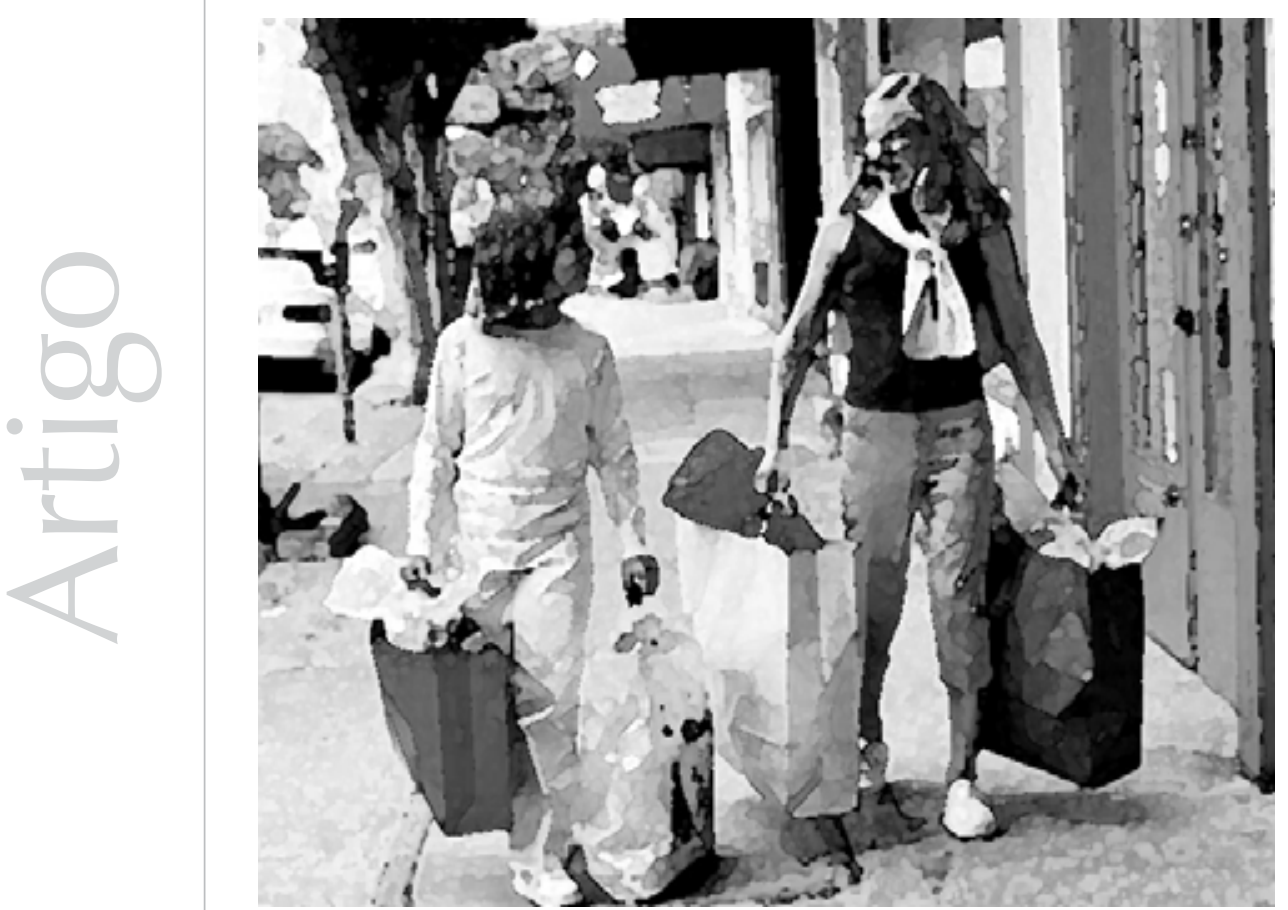
Resumo: Este artigo faz uma análise de percepções e de concepções sobre o que é a criança e resgata a evolução do conceito de infância da antiguidade aos dias atuais, associando tais mudanças à dinâmica social pelo surgimento de novas estruturas familiares e de fatores históricos, sociais, políticos e culturais. São discutidos algumas particularidades da criança e seu processo de desenvolvimento cognitivo sob a luz da teoria de Piaget, considerando a infância inserida nas grandes sociedades de consumo capitalistas e analisando como ela interpreta as informações apresentadas pelo mercado através das propagandas e outros meios. Este artigo tem como objetivo contextualizar a evolução das percepções em relação à criança, evidenciando sua inserção crescente no mercado de consumo, peculiaridades inerentes à sua idade, sua relação e comunicação com os pais e como eles são significativos no desenvolvimento de sua autonomia e capacidade crítica. O consumo exagerado se afirma culturalmente e gera consequências na infância, frutos de um processo alienante que vem sendo construído pelo sistema capitalista e reproduzido pelas pessoas. Evidencia-se, então, a precocidade das relações que se processam no interior da sociedade.

Palavras-chave: Crianças. Cultura. Desenvolvimento infantil. Desenvolvimento cognitivo. Comportamento do consumidor.

\begin{abstract}
This article analyses the perceptions and conceptions of "what the child is" and gives an account of the evolution of childhood's notion from old times to present days, associating those changes to the social dynamics through the beginning of new familiar structures and historical, social, political and cultural factors. Some child's particularities and his/her cognitive development process according to Piaget's theory are discussed, considering childhood in the large capitalist consuming societies and analysing how the child interprets the information presented by the media through advertisements and other communication ways. This article's goal is to present the evolution of the perceptions concerning the child, evidencing his/heir growing insertion in the consumption market, the peculiarities of his/her age, relationship and communication with his/her parents and how they are significative to the child's autonomy development and critical capacity. The exaggerated consumption is culturally emphasized and generates consequences during childhood, which are products of an alienating process that has been forged by the capitalist system and reproduced by society. The precocity of the relations which are processed in society is evidenced.
\end{abstract}

Keywords: Children. Culture. Childhood development. Cognitive development. Consumer behavior.

Resumen: Este artículo hace un análisis de percepciones y de concepciones sobre lo que es el niño y rescata la evolución del concepto de infancia desde la antigüedad a los días actuales, asociando tales cambios a la dinámica social por el surgimiento de nuevas estructuras familiares y de factores históricos, sociales, políticos y culturales. Son discutidas algunas particularidades del niño y su proceso de desarrollo cognoscitivo bajo la luz de la teoría de Piaget, considerando la infancia insertada en las grandes sociedades de consumo capitalistas y analizando como esta interpreta las informaciones presentadas por el mercado a través de las propagandas y otros medios. Este artículo tiene como objetivo contextualizar la evolución de las percepciones con relación al niño, evidenciando su inserción creciente en el mercado de consumo, peculiaridades inherentes a su edad, su relación y comunicación con los padres y como ellos son significativos en el desarrollo de su autonomía y capacidad crítica. El consumo exagerado se afirma culturalmente y genera consecuencias en la infancia, frutos de un proceso alienante que viene siendo construido por el sistema capitalista y reproducido por las personas. Se evidencia, entonces, la precocidad de las relaciones que se procesan en el interior de la sociedad.

Palabras-clave: Niños. Cultura. Desarrollo infantil. Desarrollo cognoscitivo. Comportamiento del consumidor.

Desde seu nascimento, a criança integra-se em um mundo de significados construídos historicamente e interage com ele inspirandose em modelos de seu meio social. De acordo com Durkheim (1973), os fatos sociais precedem o indivíduo e possuem existência própria, são externos a ele e estão além de seu controle e vontade, uma vez que a sociedade e todos os seus padrões já estão postos quando o indivíduo nasce. A criança, ao inserir-se na sociedade, adapta-se às regras dos fatos sociais de sua época e ao contexto sociocultural específico. Considerando o homem um ser social e a grande diversidade cultural existente nas sociedades, a criança foi percebida e tratada de formas distintas. Em cada contexto e época, foram construídos diferentes significados em relação à criança e ao seu papel social, produzindo-se imensa diversidade de concepções e percepções sobre a infância. As representações de infância da atualidade têm origem em um processo 
cultural, histórico, político, econômico, social e ideológico construído nas sociedades.

\section{A criança na Antiguidade}

Segundo Jaeger (2001), na Grécia antiga, o pai era a autoridade máxima, e a família da criança era seu referencial em relação à educação, à cultura, à saúde, à formação moral e à estrutura psicológica. Na Roma antiga, a família era, para a criança, sua base educacional e cultural. Enfatizava-se a formação do caráter moral dos indivíduos como elemento de diferenciação entre uma pessoa e outra. Segundo Conrad (2000), Aristóteles considera a criança incapaz de usar o pensamento e o raciocínio para alcançar a virtude. Ele vê a infância como maléfica e desastrosa, uma doença que requer cuidados especiais e educação para o futuro, sendo a criança incapaz e inoperante, cujo valor estava no potencial de desenvolvimento da infância. A criança torna-se indivíduo apenas quando atinge a idade adulta, e a infância seria uma fase em que ainda não há identidade, capacidade de discernimento para tomar decisões e pensamento autônomo. Essa fase necessita ser rapidamente superada para que o indivíduo ganhe autonomia e adentre o universo adulto, tornando-se apto para tomar decisões.

\section{A criança na Idade Média}

Na Idade Média, na Europa, as percepções sobre a criança transformam-se radicalmente. Cirino (2001) afirma que Santo Agostinho, em seu livro Confissões, reporta fatos da própria infância dos quais se envergonha, afirmando que a criança pequena já traz consigo o pecado e que sua alma não é inocente. Santo Agostinho realiza esse trabalho com afinco, no momento em que o Cristianismo se consolida como religião de grande importância sociopolítica e a Igreja se afirma como instituição. Cirino destaca a visão de Santo Agostinho sobre o fenômeno da infância:

O pensamento de Santo Agostinho, que, durante séculos, exercerá influência sobre a tradição cristã e sobre a pedagogia, postula tanto a idéia de que a infância - concebida como o período em que não se fala - é uma época desprezível quanto à perspectiva de que a maldade seria a verdade da criança antes de qualquer adestramento educativo e moral (Cirino, 2001, p.25)

Nessa época, a adolescência e a infância eram confundidas, não havendo a distinção de um limite etário que as separasse. Ariès (1975) ressalta que a "descoberta da infância" começou no século XIII, pois, até o século XII, a arte da Idade Média (pinturas, quadros, retratos, iconografias, etc.) desconhecia ou não tentava representar a infância; esse era um tema ausente na produção artística da época. Quando surge a reprodução da criança em pinturas, ela aparece exatamente como um adulto em tamanho reduzido, e sua altura e proporção eram os únicos traços que as diferenciavam. Havia grande indiferença e descaso em relação às crianças que morriam. Pelo grande índice de mortalidade infantil, a morte prematura já era prevista pelas famílias e rapidamente assimilada. Segundo Ariès, não se considerava que a criança fosse dotada de personalidade e alma, e ela vestia-se com trajes idênticos aos dos adultos, confundindose com estes em ambientes públicos e privados. A preocupação era somente o status social e a hierarquia, e as roupas de crianças e adultos distinguiam sua classe social. $\mathrm{Na}$ sociedade medieval, não havia consciência das particularidades da criança pela ausência de um tratamento próprio dirigido a elas, o que não significa que fossem desprezadas, abandonadas ou maltratadas por seus responsáveis. Segundo Áries (1975), surgem modelos de representação das crianças e da infância como o anjo, o menino Jesus e a criança nua. A imagem da Virgem com o menino Jesus no colo inspirou artistas da época, sendo referência para a reflexão sobre a maternidade e espelho para as famílias, que 
associavam a imagem à sua vida doméstica e idealizavam o papel da mãe. Posteriormente, começa-se a reproduzir a criança em multidões sempre acompanhadas dos pais, sugerindo uma imagem de dependência e de fragilidade. Os artistas destacavam os traços característicos da criança, diferenciando-a dos adultos.

\section{A criança na Modernidade}

Na Modernidade, ocorrem significativas mudanças nas concepções sobre a criança e a infância, com grande ênfase e preocupação quanto à educação e à moral, que influenciaram o pensamento dos séculos posteriores. Ariès utiliza a expressão "sentimento da infância", que se refere às percepções que se constroem a respeito da criança e da infância, assim como à forma de tratá-las e de considerá-las. Ariès salienta que, a partir do século XVI, é atribuído à criança um traje reservado à sua idade (antigos trajes que os adultos haviam abandonado há muito tempo), que a diferenciava dos adultos. A adoção de um traje peculiar à infância, que se tornou geral nas classes altas no fim do século XVI, marca um período importante na formação do sentimento da infância, pela constituição de um grupo esteticamente separado dos adultos. A criança agora era reconhecida como uma entidade separada, e havia tendências como a efeminação: tornou-se impossível distinguir um menino de uma menina até os cinco anos de idade. Nas famílias nobres e burguesas, os meninos foram os primeiros a ganhar uma particularização em seus trajes, enquanto as crianças do povo conservaram o antigo modo de se vestir que não as diferenciava dos adultos. No século $\mathrm{XVI}$, os jogos e brincadeiras de crianças e adultos eram os mesmos, e não havia proibição em relação ao fato de às crianças jogarem jogos de cartas e de azar que envolvessem dinheiro. Segundo Áries (1975), observa-se nesse período uma reforma dos costumes, sinal da renovação religiosa e moral do século XVII. Inicialmente, fazia parte do costume da época associar as crianças às brincadeiras sexuais dos adultos sem nenhuma reserva, com a adoção de linguagem vulgar e grosseira e de ações e de gestos obscenos, de brincadeiras que envolviam sexo, etc. A criança era considerada alheia e indiferente à sexualidade.

No final do século XVI, surgem moralistas e religiosos com idéias diferentes, iniciando-se uma revolução dos costumes que manifestava grande preocupação com as questões da infância, como educação, moral, pudor, comportamento sexual e hábitos. A figura da criança adquire uma conotação religiosa e casta, e mudam-se as percepções sobre a infância, com grande respeito pelas crianças em suas particularidades. Não eram mais alguns moralistas isolados, e sim, um grande movimento cujos sinais eram percebidos por toda parte, tanto em farta literatura moral e pedagógica como em práticas de devoção e cultos religiosos: "Uma noção essencial se impôs: a da inocência infantil" (Ariès, 1975, p.136). Foi construída uma concepção moral de infância que enfatizava as fragilidades da criança, associadas à ideia de inocência. Essa concepção foi uma reação contra os abusos cometidos pelos adultos e contra certos sentimentos, como a indiferença pela infância. As ideias dessa doutrina se espalharam na literatura, consolidando novas orientações no trato com as crianças. De acordo com Ariès, considerouse prejudicial deixar crianças sozinhas sem a assistência de um adulto, mimá-las em excesso, permitir que dormissem com pessoas de sexo oposto e deixá-las na companhia de criados ou desconhecidos. Tornou-se consenso a necessidade de repreendê-las para habituá-las desde cedo à seriedade. A grande preocupação dos moralistas e dos educadores em relação à decência refere-se também às conversas, leituras, músicas, arte, linguagem cotidiana e diversões, pois queriam isolar a criança para preservá-la de qualquer conteúdo indecente: 
O sentido da inocência infantil resultou, portanto, numa dupla atitude moral com relação à infância: preservá-la da sujeira da vida, e especialmente da sexualidade tolerada quando não aprovada - entre os adultos, e fortalecê-la, desenvolvendo o caráter e a razão (Ariès, 1975, p. 146).
O sentido da inocência infantil resultou, portanto, numa dupla atitude moral com relação à infância: preservá-la da sujeira da vida, e especialmente da sexualidade tolerada - quando não aprovada - entre os adultos, e fortalecê-la, desenvolvendo o caráter e a razão (Ariès, 1975, p.146).

A importância adquirida pela criança nesse período emerge de dois aspectos. O primeiro é a infância santa influenciada pelo Cristianismo, com a associação de Cristo à inocência infantil. Foi estabelecida uma religião para as crianças e a devoção do anjo da guarda lhes foi reservada, acreditandose que Jesus enviava os anjos da guarda para protegerem as crianças. Segundo Áries (1975), a imagem da alma conduzida por um anjo em forma de criança espalhase pelos séculos XVI e XVII, e a primeira comunhão se torna gradativamente a grande festa religiosa da infância e a maior manifestação do sentimento da infância na modernidade. A literatura pedagógica e moral do século XVII cita várias passagens do Evangelho, nas quais Cristo se refere às crianças. O segundo aspecto foi o grande movimento de interesse pela infância por parte de estudiosos, educadores, moralistas e pedagogos. A sociedade moderna designa um papel central à educação e à família, atribuindo grande importância ao caráter educativo no desenvolvimento da criança. No século XVIII, Rousseau marca profundamente as concepções sobre a criança. Apesar de racionalista, Rousseau dá grande ênfase à infância e à educação, colocando o sentimento como ponto central em sua visão de homem e considerando que a infância tem maneiras próprias de ver, pensar e sentir. No livro Emílio ou da Educação, Rousseau (1973) traça os caminhos para se produzir um bom adulto, afirmando que a criança pode ser educada e que a infância é uma fase tão perfeita e importante quanto a adulta. Ele entende que a criança tem um mundo próprio, e elabora uma pedagogia que enfatiza a naturalidade, a autenticidade e a inocência da criança. A partir de Rousseau, intensificou-se a tendência de valorizar a educação infantil, sua natureza e suas capacidades e inclinações, em oposição aos padrões impostos pela sociedade.

\section{A criança na Contemporaneidade}

A partir do século XVIII, as percepções sobre a infância sofrem profundas mudanças, de forma que alguns aspectos históricos da contemporaneidade colocam em questão o sentimento da infância e sugerem sua desvalorização. Uma análise da trajetória da criança da contemporaneidade no mundo ocidental traz à tona um declínio da valorização da infância, haja vista o relato de diversos atos de pedofilia e de crianças vítimas de estupro. Para Del Priore, a pedofilia está entre os tabus sexuais mais repelidos pela ideologia ocidental na contemporaneidade: "Daí a dessexualização da infância e adolescência impor-se como um valor humano fundamental de nossa civilização judaico-cristã" (Del Priore, 1996, pp. 44-45). Esse aspecto contrapõe-se a comportamentos tidos como desviantes, que enxergam as crianças como objeto de desejo.

Além da submissão sexual, a criança esteve durante muito tempo sujeita à exploração do trabalho escravo, e até hoje a questão do trabalho infantil é um problema social grave. No período da escravidão no Brasil, as crianças eram submetidas ao regime de escravidão e às práticas de crueldade e tortura. Del Priore ressalta que a criança menor de 8 anos era considerada incapaz de desempenhar atividades do tipo econômico; de 8 a 12 de idade, não eram mais crianças, e entravam no mundo dos adultos na condição de aprendizes. A criança era vista como escravo reduzido, e seu tamanho e força de trabalho eram critérios que as diferenciavam dos escravos adultos. Em grande parte da 
infância escrava, a criança não tinha pai e mãe identificados. A Lei do Ventre Livre (1871) coloca sob o poder dos senhores os filhos de escravos nascidos ingênuos, obrigando-os a criar essas crianças até que completassem 8 anos de idade. "Como vimos, o escravo permanece criança até a idade de 7 para 8 anos" (Del Priore, 1996, p. 81). Nessa idade, a criança percebia sua inferioridade social e econômica, e a passagem para a adolescência era o primeiro choque importante que a criança escrava recebia. A escravidão no Brasil representa um grande abalo no sentimento e na valorização da infância. Del Priore observa que, no século XIX, a infância continua a ser explorada no Brasil rural e em outros contextos como fábricas e indústrias, com significativo histórico de acidentes de trabalho que envolviam a infância operária.

No Brasil, o conceito menor surge no século XIX associado aos limites etários. De acordo com Del Priore (1996), o mundo jurídico descobre o menor nas crianças e adolescentes pobres das cidades que, por não estarem sob a autoridade dos responsáveis, são chamados de menores abandonados. Posteriormente, esse conceito é associado à criminalidade e serve à regulamentação das leis para menores. Surgem dois tipos de infância: uma incluída na cobertura das políticas sociais básicas, com crianças socializadas pela escola e pela família, e outra excluída das famílias e das políticas sociais, que constitui o contingente dos menores. No século XX, com o crescimento da pobreza e da violência urbana, a criança se torna objeto de políticas governamentais de caráter mais abrangente. Nos anos 60, o Estado se torna o principal responsável pela proteção e pela assistência à infância abandonada e em situações de risco no Brasil. Surge uma nova concepção de infância: a criança como sujeito de direitos civis, humanos e sociais, necessitando de direitos e cuidados especiais. Cirino (2001) sugere um retrocesso do sentimento da infância, como a exploração do trabalho infantil, o crescente número de desnutrição, o abandono, os abusos sexuais, a prostituição, a delinquência juvenil, a violência por parte da polícia e da família, a discriminação e a exclusão social. Esses fatos presentes no cotidiano são tipificados como problemas da infância na atualidade. $\mathrm{Na}$ Constituição, inúmeros direitos outorgados às crianças sugerem a continuidade do percurso de valorização da infância, mas, na prática, esses direitos reservados à infância são sempre transgredidos.

Nas sociedades capitalistas pós-modernas do século $X X$, configura-se uma nova concepção de infância: as crianças como segmento de mercado, que constituem um público de interesse das empresas por já consumirem ativamente e influenciarem seus pais a comprar, representando os promissores consumidores do futuro. Essa representação da infância que emerge na atualidade é fruto das mudanças econômicas, sociais, políticas e ideológicas ocorridas com a globalização do século XX.

\section{O consumismo das grandes sociedades capitalistas da atualidade}

As novas configurações geradas pelas transformações econômicas, tecnológicas, políticas, sociais, culturais e ideológicas ocorridas nas grandes sociedades capitalistas da contemporaneidade produziram significativas mudanças na vida das pessoas, nas relações sociais, e novas subjetividades são construídas. A sociedade de consumo e suas ideologias dominantes promovem um distanciamento do homem consigo mesmo e com a sua natureza, produzindo uma manifestação típica das grandes sociedades capitalistas da atualidade: o predomínio do ter sobre o ser. Em A Sociedade do Espetáculo, Debord (1997) afirma que o espetáculo é, 
"A força

cumulativa de um artificial independente provoca a falsificação da vida social" (Debord, 1997, pp.45-46). materialmente, a expressão da separação e do afastamento entre o homem e o homem, no qual a massa de objetos cresce e faz com que o homem fique sujeito ao seu domínio. É o ápice de uma expansão que opõe a necessidade à vida. $\mathrm{O}$ consumo excessivo torna as pessoas dependentes e submetidas ao mundo das mercadorias, sendo fabricados novos significados em relação à vida e novas percepções de mundo.

De acordo com Lipovetsky (2007), o consumismo exagerado na pós-modernidade se fundamenta nos desejos nunca alcançados, surgindo novas vontades de consumir devido a uma incapacidade de eliminar os apetites de consumo, que posteriormente geram outras procuras, uma espécie de círculo vicioso sem fim e completamente alienante, que se tornou parte da cultura das grandes sociedades capitalistas da atualidade. $\mathrm{O}$ ato de consumir adquire aspectos subjetivos próprios, transcendendo a satisfação proporcionada pela mercadoria em si e substituindo-a pela busca da satisfação em seu valor como mercadoria. As marcas e as mercadorias parecem adquirir vida própria e personalidade. Debord faz alusão a esse fenômeno, ressaltando que cada mercadoria específica luta por si mesma, não reconhecendo as outras e pretendendo impor-se em toda parte como se fosse a única. A satisfação que a mercadoria abundante já não proporciona em seu consumo passa a ser procurada no reconhecimento de seu valor como mercadoria: é o uso da mercadoria bastando a si mesmo: "Para o consumidor, é a efusão religiosa diante da liberdade soberana da mercadoria" (Debord, 1997, p. 44). O autor ressalta que o espetáculo é o momento em que a mercadoria ocupou totalmente a vida social, e não apenas a relação com a mercadoria é visível, mas nada se consegue ver além dela: o mundo que se vê é o seu mundo. $\mathrm{O}$ consumo alienado que aprisiona as pessoas no mundo da mercadoria produz uma busca incessante por uma satisfação que nunca se concretiza de fato. Nesse sentido, Cirino e Lipovetsky salientam que a prometida satisfação não alcançável leva à decepção e à tristeza, produzindo sujeitos insaciáveis, vorazes em sua demanda de consumo. A era contemporânea apresenta como sintoma mais significativo dos problemas existenciais o vazio emotivo, que se manifesta na incapacidade de sentir a vida, na perda de valores, nas crises de identidade, na ansiedade e no esvaziamento do significado das coisas. A existência perde seu sentido.

Lipovetsky (2007) e Cirino (2001) afirmam que vivemos na era do vazio, da insegurança e do imediatismo. As pessoas se lançam em uma busca desenfreada por sentido, lutando contra um vazio existencial que nunca é preenchido. A sociedade, dentro de seu contexto histórico e sociocultural, é responsável pela construção de necessidades específicas que são reproduzidas pelos indivíduos dessa sociedade, e nas sociedades consumistas não é diferente. Fabricam-se novas necessidades e desejos fundamentados em um artificial infinito que se impõe às pessoas. Como assinala Debord, a pseudonecessidade imposta pelo consumismo moderno não pode ser contrastada com nenhuma necessidade ou desejo autêntico não produzido pela sociedade e sua história. A mercadoria abundante representa a ruptura absoluta do desenvolvimento orgânico das necessidades sociais, e sua acumulação libera um artificial ilimitado: "A força cumulativa de um artificial independente provoca a falsificação da vida social" (Debord, 1997, pp.45-46).

De acordo com Lipovetsky (2007), o consumo desenfreado adquire um caráter subjetivo, no qual os gostos, os critérios individuais, os anseios e as buscas movem os desejos das pessoas, criando-se novos desejos de aceitação, de integração grupal e de reconhecimento pelo outro, além da busca de prazeres e de satisfações ilusórias que nunca se concretizam de fato, pois pautam- 
se no aspecto artificial, uma busca subjetiva e emocional por benefícios e prazeres. A paixão pelo novo e a importância que adquire o ser você mesmo mobilizam as pessoas a se sentirem especiais por adquirirem algo que classificam como a minha marca. A ideia de se sentir uma pessoa com personalidade singular assume um sentido de grande valor e faz as pessoas buscarem incessantemente uma identidade que se concretiza superficialmente. Esse objetivo se torna cada vez difícil de ser alcançado e gera incômodo e frustração nas pessoas, que tentam apoiar-se nos produtos e nas marcas acreditando que sejam os elementos necessários para a satisfação de suas demandas e para a construção de suas identidades. Em vez de se comprar um produto, compra-se a promessa de satisfação de um desejo, um conceito, um estilo de vida, tudo relacionado às marcas: "É sobre um fundo de desorientação e de ansiedade crescente do hiperconsumidor que se destaca o sucesso das marcas" (Lipovetsky, 2007, p.50).

\section{Contribuições de Jean Piaget: a criança de dois a sete anos}

Jean Piaget é um dos representantes mais expressivos do interacionismo, que explica o comportamento humano em uma perspectiva na qual o desenvolvimento das estruturas cognitivas e a construção do psiquismo são frutos da interação entre sujeito e objeto. Piaget (2001) considera a adaptação e a organização pertencentes à natureza do ser humano, que organiza suas experiências vividas e adapta-se ao que estiver experimentado. A adaptação na criança ocorre por meio dos processos de assimilação e de acomodação: "Pode-se chamar adaptação ao equilíbrio dessas assimilações e acomodações. Essa é a forma geral de equilíbrio psíquico. O desenvolvimento mental aparecerá, então, em sua organização progressiva como uma adaptação sempre mais precisa à realidade" (Piaget, 2001, p.17). De acordo com Piaget, do ponto de vista social, a acomodação nada mais é do que a imitação e o conjunto de operações que possibilitam à criança submeter-se aos exemplos e aos imperativos do grupo em que está inserida. A assimilação consiste na incorporação da realidade à atividade e às perspectivas do eu. "A assimilação e a acomodação são, portanto, os dois pólos de uma interação entre o organismo e o meio que é a condição para qualquer funcionamento biológico e intelectual" (Piaget, 2003, p.360).

Piaget (2001) divide o processo de desenvolvimento mental da criança em seis estágios: sensório-motor ou período de lactância, composto por três subestágios (do nascimento aos dois anos), pré-operacional (dois aos sete anos), operações concretas (sete aos doze anos) e operações formais (a partir dos doze anos, marcando o início da adolescência). As estruturas progressivas dos estágios (formas sucessivas de equilíbrio) são maneiras de organização da atividade mental da criança nas dimensões individual e social, sob um duplo aspecto: motor ou intelectual e afetivo.

Neste estudo, o estágio pré-operacional (dois a sete anos) é destacado por ser a faixa etária caracterizada pelo surgimento da linguagem, pelas relações sociais de submissão aos adultos e pela inserção da infância no consumismo. Com a linguagem, os comportamentos da criança são profundamente modificados nas dimensões afetiva e intelectual. Piaget (2001) enfatiza que a troca e a comunicação entre os indivíduos são a consequência mais evidente do surgimento da linguagem, e ressalta três consequências essenciais para o desenvolvimento mental da criança nesse estágio: início da socialização da ação (troca entre os indivíduos), pensamento (interiorização da palavra com base na linguagem interior e nos signos) e intuição 
(interiorização da ação, que se reconstitui no plano intuitivo das imagens e das experiências mentais). Se a criança se relacionava apenas com o universo físico, agora está diante de dois mundos novos: o mundo social e o das representações interiores. Piaget evidencia o desenvolvimento de uma submissão inconsciente, intelectual e afetiva, devida à coação espiritual exercida pelo adulto. Um eu ideal se propõe à criança, e os exemplos vindos do alto serão modelos que a criança deve procurar copiar ou igualar:

Existem os fatos de subordinação e as relações de coação espiritual exercida pelo adulto sobre a criança. Com a linguagem, a criança descobre as riquezas insuspeitas de um mundo de realidades superiores a ela; seus pais e os adultos que a cercam the aparecem já como seres grandes e fortes, como fontes de atividades imprevistas e misteriosas. Mas agora esses mesmos seres revelam seus pensamentos e vontades, e esse novo universo começa a impor-se com sedução e prestígio incomparáveis (Piaget, 2001, p.26)

Em relação ao pensamento da criança de dois a sete anos, Piaget (2001) ressalta que a assimilação egocêntrica marca o início do pensamento e da socialização. Piaget (1973) enfatiza que, do ponto de vista do pensamento, as trocas interindividuais caracterizam-se por um egocentrismo a meio caminho do individual e do social, definindo-se por uma indiferenciação relativa do ponto de vista próprio e do outro. Há dois polos extremos, e a maioria dos atos do pensamento infantil oscila entre estas direções contrárias: o pensamento egocêntrico puro e o pensamento intuitivo.

O pensamento egocêntrico puro é um dos polos. Piaget associa-o ao jogo simbólico, no qual os jogos de imaginação e imitação constituem uma atividade real do pensamento essencialmente egocêntrica que visa a satisfazer o eu, transformando o real em função dos desejos: “O jogo simbólico não é um esforço de submissão do sujeito ao real, mas, ao contrário, uma assimilação deformada da realidade ao eu. De outro lado, a linguagem intervém nessa espécie de pensamento imaginativo, tendo como instrumento a imagem ou símbolo" (Piaget, 2001, p.29). Com a função simbólica, desenvolve-se a capacidade de representar objetos, ações ou acontecimentos através de símbolos (imagens mentais, gestos, palavras, sonhos, desenhos, etc). Para Pulaski, a criança emprega símbolos e, através do faz de conta, assimila e consolida como parte de sua experiência os costumes observados em seu ambiente: "Ao imitar a fala, o comportamento e as atividades dos adultos, as crianças aprendem a ajustar-se a novas situações em seu mundo" (Pulaski, 1986, p.40).

O egocentrismo é uma das características dominantes do pensamento da criança no estágio pré-operacional. Piaget (2001) afirma que, em vez de sair de seu próprio ponto de vista para coordená-lo com o dos outros, a criança permanece inconscientemente centralizada em si mesma. Esse egocentrismo diante do grupo social reproduz e prolonga o do lactente frente ao universo físico. Como afirma Piaget (1977b), por mais dependente que seja das influências intelectuais ambientes, a criança nova as assimila a seu modo, reduzindo-as ao seu próprio ponto de vista e deformando-as. A criança é egocêntrica pela inconsciência de sua subjetividade no plano social e incapaz de se situar de outra perspectiva, atribuindo aos outros a sua própria visão das coisas. Segundo Piaget (1977b), o egocentrismo intelectual nada mais é que falta de coordenação e uma ausência de grupamento das relações com os outros e com as coisas. A supremacia do ponto de vista próprio e a centração intuitiva em função da ação própria expressam uma indiferenciação inicial e uma assimilação deformante, porque determinada pelo único ponto de vista possível inicialmente. Para Piaget (2001) , há uma indiferenciação entre 
o eu e a realidade exterior, aqui representada pelas outras pessoas, pois a criança está muito centrada em si mesma e experimenta tudo em termos de si própria, sendo incapaz de desenvolver outros pontos de vista. $\mathrm{O}$ raciocínio da criança, por volta de dois a quatro anos, "é muito influenciado por suas próprias vontades e desejos, como se ela visse o mundo através de seus próprios desejos e tentasse transpor obstáculos pensando a seu modo" (Bee, 1977, p.146). Coutinho e Moreira (2001) salientam que o egocentrismo da criança, como traço intelectual, manifestase na representação do mundo, nos raciocínios e nos comportamentos sociais. A criança atribui aos objetos e acontecimentos qualidades subjetivas, impondo uma perspectiva particular às diversas situações e transformando a realidade exterior em função de seus desejos.

O pensamento intuitivo é o outro polo, que, segundo Piaget, enseja uma elaboração intelectual incompleta, pré-lógica, pois ainda imita de perto os dados perceptivos, ao mesmo tempo centrando-os a seu próprio modo: "A intuição continua fenomenista, porque imita os contornos do real sem os corrigir, e egocêntrica, porque constantemente centrada em função da ação do momento" (Piaget, 1977b, p.141). Conforme o autor, há relação estreita entre o caráter egocêntrico das trocas interindividuais próprias dessa faixa etária e o caráter intuitivo do pensamento. Por um lado, todo pensamento intuitivo centra-se em uma configuração estática, não atingindo uma decentração suficiente. Essa centração intuitiva implica o egocentrismo, no qual ela é uma prioridade do ponto de vista subjetivo imediato (perceptivo). Por outro lado, todo pensamento egocêntrico centra os objetos em função da atividade própria do momento, implicando o pensamento por imagem ou intuição, em oposição à objetividade.

\section{A criança no consumismo e o relacionamento entre pais e filhos}

As contribuições de Piaget sobre o processo de desenvolvimento cognitivo da criança de dois a sete anos sinalizam características dessa faixa etária que abrem caminho para sua inserção na sociedade consumista. A precocidade das interações entre a criança e seu ambiente sociocultural é evidenciada na assimilação da cultura do consumo, pela infância, desse contexto, em que ela se vê bastante exposta aos estímulos das propagandas e ao bombardeio feito pelo mercado através das mídias. Essa faixa etária marca a inserção da criança no mundo do consumismo devido ao seu egocentrismo, ao surgimento da linguagem e às primeiras relações sociais, de forma que tais particularidades atuam em harmonia com as estratégias das empresas para atingir o público infantil. Com o advento da linguagem, evidencia-se a troca e a comunicação da criança com a família. A submissão intelectual e afetiva devida à coação espiritual exercida pelo adulto propõe à criança um eu ideal, de forma que exemplos dos pais e de outras pessoas serão modelos que ela imitará. A criança se espelha nos adultos, que frequentemente acumulam bens materiais e de consumo, aprendendo, através do exemplo direto dos pais consumistas, a necessidade de comprar e de consumir mais produtos, associada à ideia da satisfação de suas necessidades e desejos. Frequentemente, a criança recebe dos pais uma educação que estimula o hiperconsumo. O surgimento do universo simbólico faz que a criança assimile como parte de sua experiência os hábitos que vê em seu ambiente, imitando comportamentos e atitudes dos pais. Observando os pais sempre a consumir produtos, a criança reproduz e copia tais comportamentos sem crítica, incorporando essas práticas. 
A criança tende a demandar um grande número de produtos que despertam seu interesse, sejam bens materiais, sejam de consumo. Dos quatro aos seis anos, suas preferências costumam ser acentuadas, e fazem muitas solicitações aos pais para comprarem os produtos que desejam. Se há o consentimento dos pais, a criança se submete progressivamente à cultura consumista e ao mundo das mercadorias sem ter consciência disso, pois, com a predominância do pensamento egocêntrico, ela atribui aos objetos qualidades subjetivas de seu eu e guia-se por seus desejos e vontades. Piaget (1977a) sustenta que, no desenvolvimento, o apogeu do egocentrismo coincide com o da pressão dos exemplos e das opiniões do meio. A criança aprende que consumir é bom e prazeroso, principalmente quando há exemplo dos pais, a quem imita. Impondo sua própria perspectiva às coisas, dirigida por seus desejos, espelhandose nos modelos transmitidos pelos pais e tendo o seu aval nessa perspectiva, a criança começa a apropriar-se da cultura do consumo desenfreado, lapidando-se sua nova necessidade: o consumo. As mensagens das empresas na divulgação de suas mercadorias atingem os consumidores através das mídias convencionais (televisão, rádio, outdoors, revistas, jornais) e mídias interativas (internet), que são um grande triunfo do consumismo e que estão efetivamente presentes na vida das crianças. Estas facilmente assemelham essas experiências vividas à sua vida cotidiana, associando-as aos eventos e às pessoas de seu meio social. A criança de dois a sete anos ainda não possui crítica para analisar os conteúdos recebidos, não considerando outras perspectivas além da sua. Isso ocorre devido ao egocentrismo da criança dessa faixa etária, marcado pela indiferenciação entre o eu e a realidade exterior, ou seja, a não distinção entre o ponto de vista próprio e o do outro. Aliado a isso, a criança se guia por seus desejos; incapaz de se situar de outra perspectiva, ela se encontra amplamente sugestionável e influenciável pelos conteúdos apresentados pela televisão, pela internet e pelas demais mídias:

Pelo fato de o egocentrismo resultar de simples indiferenciação entre o ego e o alter, a criança acha-se exposta, durante o período pré-operacional, a todas as sugestões e constrições do meio ambiente, às quais se acomodará sem crítica, precisamente por não estar consciente do caráter próprio de seu ponto de vista (Piaget, 1977a, p.162)

As propagandas são poderosas ferramentas do consumismo, pois seduzem o consumidor e atraem-no para o consumo. O investimento das empresas em produtos voltados para o segmento infantil tem crescido, e a propaganda se torna cada vez mais presente no universo da criança. Crianças de dois a sete anos apreciam o espetáculo ofertado pelas propagandas, suas cores, músicas, personagens animados e o enredo da história. Karsaklian (2004) afirma que as crianças gostam de propagandas que as divirtam. As que utilizam desenho animado são muito bem recebidas, e, quando acompanhadas de uma canção atraente, favorecem o interesse da criança pela propaganda. Os jingles e as frases de efeito contribuem para a memorização e a associação do comercial a uma determinada marca, assim como as que evidenciam determinados valores também despertam o interesse da criança. O raciocínio da criança de dois a sete anos baseia-se em sua percepção imediata, lida com a realidade percebida através do pensamento intuitivo e considera somente a aparência dos objetos, informações, experiências e acontecimentos, sem levar em conta outras dimensões de seus conteúdos. De acordo com Karsaklian, o que atrai a atenção das crianças é a diversão proporcionada pelas propagandas e seus impactos visuais e auditivos, como um slogan de fácil assimilação que se repete ou um jingle bem executado. As crianças tendem a lembrar-se do que as personagens fazem e não daquilo que são, registrando 
"O pensamento intuitivo está a cada instante centrado numa relação dada, é fenomenista e só atinge do real a sua aparência perceptiva: está, portanto, à mercê das sugestões da experiência imediata, que ele copia e imita, em vez de corrigir" (Piaget, 1977b, p.161). melhor a imagem de um produto que seja manipulado por essas personagens. As empresas utilizam essa técnica inserindo o produto na ação apresentada para chamar a atenção da criança, visto que o fato de verem a marca inserida em uma propaganda influi no momento da escolha. Diante de uma propaganda ou de um produto lançado pelo mercado, a criança pode considerar seu conteúdo agradável e ter sua atenção atraída, assim como o seu interesse e a sua curiosidade despertados, o que mobilizaria seus afetos e emoções. Surge o desejo de ter ou de consumir aquele produto, pois a criança, apoiando-se apenas no que é aparente através da percepção imediata dos estímulos, julga que ele lhe trará prazer e felicidade. Muito centrada em si e demasiadamente influenciada por seus desejos e vontades, a criança vê o mundo e transforma as informações recebidas das mídias em função de seus próprios desejos. A experiência imediata das informações recebidas governa o seu campo perceptivo, que lida com os impactos das informações auditivas e visuais utilizando o pensamento por intuição, e não a objetividade. A criança apreende os dados de sua percepção imediata atribuindo-os a si mesma e ao seu ponto de vista, de forma que o seu pensamento intuitivo faz que ela lide com os estímulos das propagandas sem análise ou crítica, uma vez que a centração intuitiva de seu pensamento é prioridade do ponto de vista subjetivo e perceptivo. Dessa forma, a criança está aberta às sugestões do aparente que se mostra a ela, quando os estímulos apresentados são agradáveis aos seus olhos: "O pensamento intuitivo está a cada instante centrado numa relação dada, é fenomenista e só atinge do real a sua aparência perceptiva: está, portanto, à mercê das sugestões da experiência imediata, que ele copia e imita, em vez de corrigir" (Piaget, 1977b, p.161).

A técnica utilizada por empresas, que associa certa marca a estímulos como frases repetitivas e marcantes, personagens animados e músicas atraentes, geralmente surte efeito na criança de dois a sete anos devido a generalizações indevidas do pensamento infantil. Ela é incapaz de identificar as relações concretas entre a marca e os estímulos visuais e auditivos que a acompanham em uma propaganda e de refletir sobre essa associação, pois ainda não desenvolveu as operações lógicas do pensamento. Propagandas com animais, animais personificados ou objetos falantes tendem a ser bem aceitas pelas crianças e despertam seu interesse, visto que o animismo é característico dessa faixa etária. Piaget (2001) define o animismo como a tendência a conceber as coisas como vivas e dotadas de intenção, que exprime uma confusão ou indissociação entre o mundo interior (subjetivo) e o universo físico. A propaganda estabelece um elo com as fantasias da criança ao promover histórias que as conduzem ao sonho, em harmonia com o universo simbólico da criança que surge com a linguagem e que evidencia o pensamento imaginativo. Piaget sustenta que podemos classificar entre os símbolos individuais toda imaginação mental, e que a função simbólica se explica pela formação das representações (afetivas e cognitivas). As crianças, empregando símbolos nas brincadeiras de faz de conta, muitas vezes reproduzem situações reais de consumo de coisas que lhes são agradáveis, como comprar um carro, ir ao shopping fazer compras, etc.

A inserção da criança de dois a sete anos no mundo do consumismo é diretamente proporcional à qualidade e às configurações dos relacionamentos estabelecidos entre os pais e os filhos, de forma que há atitudes dos pais que podem estimular o consumo infantil e atitudes que podem desencorajá-lo. Nesse cenário, é absolutamente relevante considerar o sentimento da infância dos pais, ou seja, quais percepções e concepções de criança eles têm, como tratam a infância e como estabelecem as relações com os filhos. O 
ambiente familiar como lugar de transmissão é geralmente o primeiro grupo social no qual a criança se insere, e, nesse sentido, as percepções dos pais sobre o que é ser criança são indissociáveis dos relacionamentos estabelecidos com os filhos.

Segundo Maldonado (1981), acreditando-se que a criança não seja capaz de escolher e que não tenha vontade própria, a tendência é tentar dominá-la e vigiá-la. Vendo-a como um ser selvagem, tenta-se domá-la impondo-Ihe nossos valores e padrões. Considerando-a um ser frágil, procura-se protegê-la excessivamente, omitindo-lhe fatos importantes da vida e enganando-a. Rogers (1973) afirma que tais concepções são um grande obstáculo ao crescimento da criança e entram em conflito com sua condição de constante desenvolvimento, característica inerente ao ser humano. Ao tentar impor valores, domar, dominar ou proteger excessivamente a criança, os pais estão extinguindo as condições necessárias para desenvolver plenamente as potencialidades e a autonomia dos filhos. A criança é uma pessoa em processo permanente de desenvolvimento e de atualização, de modo que, se os pais criarem relações autênticas com os filhos, encarandoos e aceitando-os como pessoas, estarão proporcionando condições concretas para o seu crescimento.

O egocentrismo, como tendência natural da criança dessa faixa etária, está vinculado às interações da criança com o outro, e os pais podem ajudá-la a superá-lo, dirigindo-se à autonomia. No entanto, muitas vezes os pais não fazem isso e atrasam o desenvolvimento moral e intelectual da criança. Piaget (1977a) conclui que somente a cooperação liberta a criança de seu estado inicial de egocentrismo inconsciente. A coação do adulto reforça os traços próprios do egocentrismo, encorajando a criança a perseverar em suas tendências específicas e que são importunas em relação ao desenvolvimento social. Enquanto a criança, com uma liberdade de ação suficiente, sai espontaneamente do egocentrismo dirigindo inteiramente seu ser para a cooperação, o adulto age constantemente reforçando o egocentrismo infantil nos aspectos intelectual e moral.

Piaget (1977a) afirma que, na família, é muito comum que o prestígio da palavra predomine sobre qualquer experiência ativa e qualquer discussão livre. A palavra adquire uma consistência própria e independente da realidade. Piaget chama esse fenômeno de verbalismo, produto do egocentrismo infantil e da união do sincretismo linguístico espontâneo da criança com a coação verbal do adulto. Se o adulto coopera com a criança, discutindo com ela em pé de igualdade, sua influência conduz à análise e à reflexão. Se sua palavra se reveste de autoridade, à medida que o ensinamento verbal prevalece sobre a experiência, o adulto consolida o verbalismo infantil. Se os pais consolidam o verbalismo, além de não estarem contribuindo para o crescimento da criança, estão reforçando suas tendências egocêntricas e retardando seu desenvolvimento. A autoridade da palavra e das regras morais reveste os relacionamentos entre pais e filhos, de modo que essas relações tendem a tornar-se superficiais e a basear-se no valor das imposições morais do adulto. Piaget faz uma crítica às atitudes da maioria dos pais, considerando que muitos são "medíocres psicólogos e praticam a mais contestável das pedagogias morais. É talvez nesse domínio que destacaríamos com mais acuidade quanto pode ser amoral acreditar demais na moral e quanto um pouco de humanidade vale mais que todas as regras" (Piaget, 1977a, p.167). Piaget ressalta que 
o adulto induz a criança à noção objetiva da responsabilidade, e aponta o esforço dos pais para apanhar a criança em falta, a multiplicidade das ordens (alguns pais são como os governantes sem inteligência, que se limitam a acumular as leis, desprezando as contradições e as confusões resultantes dessa acumulação), o prazer de aplicar sanções e o prazer de usar sua autoridade (acreditandose que é preciso "quebrar a vontade da criança" ou "fazer sentir à criança que há uma vontade superior à dela"). Geram-se tensão e problemas, que os pais muitas vezes atribuem à maldade inata da criança e ao pecado original.

O relacionamento entre pais e filhos é essencial em relação ao processo gradativo de autonomia da criança e às influências de seu meio social. Maldonado (1981) enfatiza ser essencial que os pais adotem atitudes que estimulem a autonomia da criança (principal manifestação de seu crescimento), seu poder de julgamento, senso crítico e capacidade de escolha. Educar para o desenvolvimento da autonomia na infância pressupõe dar-lhe oportunidade de escolher (delimitando as margens de escolhas) e responsabilidades (deixando gradativamente de fazer por ela o que já é capaz de fazer sozinha e não intervindo em situações com as quais ela já é capaz de lidar). Para Maldonado, quando se pensa que a criança não está entendendo nada ou que não tem problemas, torna-se muito difícil para ela lidar com as contradições a que fica exposta, pois o pensamento infantil, em geral, caracteriza-se por generalizações indevidas, que causam preocupação e ansiedade às crianças. "A criança sente-se mais tranqüila e segura quando é oficialmente informada do que está acontecendo e quando recebe ajuda para expressar abertamente dúvidas e sentimentos" (Maldonado, 1981, p.37).
Piaget enfatiza que a coação moral do adulto (respeito unilateral) resulta na heteronomia, e a cooperação resulta na autonomia. É um sinal de autonomia a criança descobrir que a veracidade é necessária nas relações de simpatia e de respeito mútuos, e, nesse caso, a reciprocidade relaciona-se à autonomia: "Com efeito, há autonomia moral quando a consciência considera como necessário um ideal, independente de qualquer pressão exterior" (Piaget, 1977a, p.172). Piaget ressalta que toda relação entre pais e filhos que envolva coação moral do adulto e extinção da reciprocidade e do respeito tende a resultar na heteronomia: "A autonomia só aparece com a reciprocidade, quando o respeito mútuo é bastante forte, para que o indivíduo experimente interiormente a necessidade de tratar os outros como gostaria de ser tratado" (Piaget, 1977a, p.172).

É imprescindível que, desde cedo, os pais estabeleçam com os filhos uma relação de confiança, transparência e honestidade. Maldonado (1981) ressalta que muitos pais contam mentiras aos filhos sobre vários aspectos, enganando-os ou omitindo coisas importantes da vida, o que gera conflitos psíquicos na criança quando ela precisar lidar com as contradições entre o que vê e o que os pais contaram. O prejuízo de seu desenvolvimento intelectual é decorrente de tais conflitos, assim como a criança pode colocar em dúvida a integridade dos pais e perder a confiança neles. É fundamental que os pais sejam sinceros e autênticos com os filhos, sendo de grande valia ensinar à criança comportamentos e atitudes que estimulem seu crescimento e o processo gradativo de aquisição de sua autonomia. É imprescindível incentivar sua capacidade crítica, sua criatividade e exercitar seu poder de escolha, assim como ajudá-la a entender as consequências que decorrerão 
de suas escolhas. Conceder liberdade à criança para tomar decisões é fundamental, pois faz que ela adquira consciência de sua capacidade de escolher e de ter certa liberdade para isso, criando-lhe um senso de responsabilidade muito positivo. A criança aprende que, dependendo de sua escolha, as consequências poderão ser boas ou ruins para ela.

\section{Considerações finais}

A criança como ser social se adapta às contingências históricas, sociais, ideológicas, políticas e culturais de cada época e aparece, nessa perspectiva ampla, como criatura maldita, pecaminosa, confundida com os adultos, ser inocente, mão de obra barata, segmento de mercado, vítima de violência e pedofilia, sujeito de direitos, etc. São várias as formas de encarar e de retratar a infância. Os pressupostos social (contexto histórico-cultural do consumismo), individual (particularidades do desenvolvimento mental da criança de dois a sete anos) e familiar (relacionamento entre pais e filhos) fornecem subsídios para a análise do consumo infantil. A inserção da infância no consumismo condiciona-se à cultura do consumo e à qualidade do relacionamento entre pais e filhos, que, por sua vez, depende das percepções dos pais sobre a criança. As atitudes dos pais que promovem a autonomia da criança e seu desenvolvimento crítico se opõem à alienação da criança ao consumo excessivo. Atitudes marcadas por coação, verbalismo, imposição e controle conduzem a criança à heteronomia, aproximam-na da alienação e tornam-na mais propensa à cultura do consumo. Os comportamentos dos pais e a cultura familiar, que servirão de modelo de socialização da criança, são determinantes na assimilação da cultura do consumo pela infância. As características do desenvolvimento cognitivo da criança de dois a sete anos e suas interações com o meio descritas por Piaget oferecem condições legítimas para a inserção da infância no mundo do consumo. O consumismo, como fenômeno de produção de cultura, abriga a construção de um processo alienante constantemente reproduzido pelas pessoas e gera novas percepções sobre a infância. As propagandas produzem uma realidade distorcida, fundamentada na apresentação de conteúdos para moldar comportamentos e criar conceitos falsos. Criam-se novas representações sobre o mundo real, deformando-se uma pequena parte de determinada realidade. Essa parte já ilusória é comumente percebida pelo consumidor como totalidade. Certos conteúdos possuem grande capacidade de consolidar modelos falsos de como viver bem, sentir-se, ter felicidade, conforto, sucesso, bem-estar, além de sustentar padrões de feio e bonito, bom e ruim, etc. Há relações entre o imediatismo próprio do consumismo da pós-modernidade e o imediatismo perceptivo que a criança de dois a sete anos experimenta, havendo prevalência do desejo nessas dimensões. Nesse sentido, um bom relacionamento entre pais e filhos proporciona condições para o desenvolvimento de uma criança autônoma para que, em certo momento de sua vida, se aproprie profundamente de si mesma e se reconheça como ser dotado de liberdade e responsável por seus atos. Da mesma forma, poderá ter consciência da cultura consumista na qual se insere e questioná-la, escolhendo livremente seu próprio caminho, seu estilo de vida, suas preferências, optando por recusar o aprisionamento ofertado pelo mundo artificial do consumo de mercadorias. 


\section{Tiago Bastos de Moura}

Discente do curso de Psicologia da Faculdade de Ciências Humanas da Universidade FUMEC, Belo Horizonte - MG - Brasil.

E-mail: tiagobastospsicologia@gmail.com

\section{Flávio Torrecilas Viana}

Discente do curso de Psicologia da Faculdade de Ciências Humanas da Universidade FUMEC, Belo Horizonte - MG - Brasil.

E-mail: flaviotorrecillas@yahoo.com.br

\section{Viviane Dias Loyola}

Mestre em Sociologia pela Universidade Federal de Minas Gerais e docente da Faculdade de Ciências Humanas da Universidade FUMEC, Belo Horizonte - MG - Brasil.

E-mail: vividl@hotmail.com

\section{Endereço para envio de correspondência:}

Rua Uberlândia, 530, Carlos Prates. CEP: 30710-230. Belo Horizonte, MG.

Recebido 23/05/2011, 1a Reformulação 28/01/2013, Aprovado 08/02/2013.

Ariès, P. (1973). História social da criança e da família. Rio de Janeiro: Zahar Editores.

Bee, H. (1977). A criança em desenvolvimento (7a ed.). Porto Alegre: Artmed.

Cirino, O. (2001). Psicanálise e psiquiatria com crianças: desenvolvimento ou estrutura? Belo Horizonte, MG: Autêntica.

Conrad, H. M. (2000). O desafio de ser pré-escola. As idéias de Friedrich Froebel e o início da educação infantil no Brasil. Dissertação de mestrado. Escola de Educação e Humanidades, Pontifícia Universidade Católica do Paraná, Curitiba, PR.

Coutinho, M. T. C., \& Moreira, M. (2001). Psicologia da educação: um estudo dos processos psicológicos de desenvolvimento e aprendizagem humanos, voltado para a educação (9a ed.). Belo Horizonte, MG: Lê.

Debord, G. (1997). A sociedade do espetáculo (E. S. Abreu, trad.). Rio de Janeiro: Contraponto.

Del Priore, M. (Org.). (1996). História da criança no Brasil (4a ed.). São Paulo: Contexto.

Durkheim, E. (1973). As regras do método sociológico. São Paulo: Companhia Editora Nacional.

Jaeger, W. W. (2001). Paidéia: a formação do homem grego (4a ed., A. M. Parreira, trad.). São Paulo: Martins Fontes.

Karsaklian, E. (2004). Comportamento do consumidor (2a ed.). São Paulo: Atlas.
Lipovetsky, G. (2007). A felicidade paradoxal - ensaio sobre a sociedade de hiperconsumo. São Paulo: Companhia das Letras.

Maldonado, M. T. (1981). Comunicação entre pais e filhos (22a ed.). Petrópolis, RJ: Vozes.

Piaget, J. (1973). Estudos sociológicos (R. Di Piero, trad.). Rio de Janeiro: Forense.

Piaget, J. (1977a). O julgamento moral na criança (E. Lenardon, trad.). São Paulo: Mestre Jou.

Piaget, J. (1977b). Psicologia da inteligência (N. C. Caixeiro, trad.). Rio de Janeiro: Zahar Editores.

Piaget, J. (2001). Seis estudos de psicologia (24a ed., M. A. M. D'Amorim \& P. S. L. Silva, trads.). Rio de Janeiro: Forense Universitária.

Piaget, J. (2003). A construção do real na criança (3a ed., R. A. Vasques, trad.). São Paulo: Ática.

Pulaski, M. A. S. (1986). Compreendendo Piaget. Rio de Janeiro: LTC.

Rogers, C. R. (1973). Liberdade para aprender (4a ed., E. G. M. Machado \& M. P. Andrade, trads.). Belo Horizonte, MG: Interlivros.

Rousseau, J. J. (1973). Emílio ou da educação (2a ed., S. Milliet, trad.). São Paulo: Difusão Européia do Livro. 